LVCENTVM, XLI, 2022, 231-246

ISSN: 0213-2338 | ISSN-e: 1989-9904

https://doi.org/10.14198/LVCENTVM.20311

Cómo citar este artículo / How to cite this article: López Gómez, H. (2022). Las funciones institucionales de las mujeres de la familia de Augusto: Octavia, Livia y Julia. Lucentum, XLI, 231-246. https://doi.org/10.14198/LVCENTVM.20311

\title{
Las funciones institucionales de las mujeres de la familia de Augusto: Octavia, Livia y Julia
}

\author{
The institutional role of women in Augustus' household: Octavia, Livia and \\ Julia
}

Helena López Gómez, Universidad de Santiago de Compostela, España, helena.lopez.gomez@outlook.com, https://orcid.org/00000003-0394

Recepción: 30/06/2021

Aceptación: 12/01/2022

\section{Resumen}

El presente artículo pretende ofrecer una visión sobre el papel institucional desarrollado por las principales mujeres de la familia de Augusto. De esta forma nos proponemos entender la forma en que el «cargo» de emperatriz romana se comienza a perfilar a inicios del Imperio. Para ello se tiene en cuenta la labor precursora de muchas mujeres tanto de la legendaria monarquía como de la República que, con sus acciones audaces captaron la atención de los historiadores antiguos y comenzaron la senda de empoderamiento femenino, reconociéndose su relevancia en ciertos aspectos de la vida pública y política. Estas mujeres ocupan los relatos de los autores en momentos puntuales, como Tanaquil o Lucrecia en época monárquica o Cornelia, Hortensia o Fulvia en la República. Sin embargo, las mujeres de las familias imperiales y, concretamente, las de la domus Augusta, son las primeras en desarrollar un rol público constante y sistemático. Junto a la mayor parte de emperadores se encuentran mujeres poderosas que los acompañan. Así pues, en las primeras décadas del principado se da la entrada de la mujer en el ámbito del poder de una forma más abierta, reconociéndose su propia relevancia. En este sentido, en el artículo se analiza cómo, pese a la naturaleza conservadora del nuevo régimen de Augusto, se permitió este avance en la posición pública femenina sin que ello supusiese una inversión en los roles de género o un revuelo para la sociedad del momento. A través de las figuras de Octavia, Livia y Julia se estudiará la forma en que se comenzó a perfilar la posición de la mujer en el poder a través de su labor institucional como parte de la familia imperial. Así pues, estas mujeres empezarán a tener un papel propio en un terreno antes vedado. La transición culminará con las condiciones especificadas en el testamento del princeps en relación a la situación que su viuda debía mantener tras su muerte. Con ello, se consolidarán las bases del rol de emperatriz y Augusta para las restantes generaciones del Alto Imperio.

Palabras clave. Emperatrices; Augusto; mujeres; Octavia; Livia; Julia; Principado.

\begin{abstract}
The main purpose of this paper is to offer a glimpse into the institutional position developed by women in Augustus' household. This way, I will try to explain how, and through which means, the «role» of Roman empress took shape during the early Principate. For this, the ground-breaking work of many women from the legendary Monarchy and the Republic is taken into account. These women, by their bold actions, caught the attention of ancient historians and began the path for women's empowerment, their relevance in certain aspects of public and political life being recognised. These women take up the work of many historians at specific moments, such as Tanaquil or Lucretia in the monarchic period, or Cornelia, Hortensia or Fulvia during the Republic. However, women from imperial families, and specifically those from the domus Augusta, were the first to develop a constant and systematic public role. Most of the emperors were accompanied by powerful women. During the first decades of the Principate, women access power in a more direct and open way, their own relevance being recognized. This paper analyses how, despite the conservative nature of Augustus' new regime, the advancement in the public position of women was allowed, without this meaning a reversal of gender roles or turmoil for the society of that time. Through the figures of Octavia, Livia and Julia, I will try to analyse how the foundations for the position of the Roman woman in power were laid. These women will, thus, begin to have a role of their own in a previously forbidden terrain. The transition will culminate with the conditions written and specified in the will of the princeps in relation to the situation and role that Augustus' widow was to maintain after his death. With this, the foundations of the role of Roman empress and Augusta would be consolidated for the remaining generations of the High Empire.
\end{abstract}

Key words. Empresses; Augustus; women; Octavia; Livia; Julia; Principate. 


\section{INTRODUCCIÓN}

El establecimiento de una nueva realidad política en época de Augusto llevó consigo ciertos cambios sociales en la cúspide del gobierno romano. El nuevo líder se apoyaba para su gobierno en aquello que era conocido, el personal de su domus. En este contexto, las mujeres no tendrían por qué haber desarrollado un papel propio dentro de la nueva política. Las matronas de las importantes familias políticas romanas se mantuvieron durante siglos en la oscuridad y acataron, en general, las decisiones masculinas siendo las protagonistas de las alianzas matrimoniales con signo político. Pese a ello, debe destacarse que las mujeres de la legendaria época monárquica y de la República fueron las precursoras de las emperatrices y dan comienzo a la senda de empoderamiento femenino. Algunas de ellas captaron la atención de los historiadores antiguos con sus acciones. Entre estas destacan la figura de Cornelia, madre de los Graco; la de Hortensia, hija del orador Hortensio, quien dirigió un discurso en el foro; Fulvia, esposa de Antonio, quien fue capaz de reclutar un ejército con sus propios medios o la propia Cleopatra, reina de Egipto quien, pese a sus excelentes dotes de gobierno, paso a la posteridad como una mera embaucadora culpable de la desgracia de Marco Antonio ${ }^{1}$. Algunas fueron loadas por la crítica contemporánea y posterior, pero, en la gran mayoría de los casos, cuando las mujeres se salían de los patrones considerados tradicionales y aceptables y su influencia se hacía más evidente, los autores del momento las solían presentar con tintes oscuros $\mathrm{y}$, generalmente, de forma harto despectiva (Fischler, 1994: 188 ss.; Saquete Chamizo, 2018: 316). De esta forma, era más habitual que su influencia y patronazgo, cuando contaba con fines políticos, se dejase sentir en las sombras, dentro de la domus o entre círculos de mujeres (Dixon, 1983; Cortés Tovar, 2005).

Sabemos que en el Alto Imperio también se dio gran protagonismo público (sobre todo si lo comparamos con la época anterior) a las mujeres de las familias de los principes. El nuevo papel otorgado a las mujeres de su casa es una característica más de las muchas peculiaridades del gobierno de Augusto (Cenerini, 2016). Surge, como consecuencia, la pregunta de cómo se gestó este papel que las féminas imperiales pasaron a desarrollar. La cuestión es especialmente intrigante en el caso de Augusto, de quien sabemos, gracias a sus leyes sobre el matrimonio, que tenía una visión tradicional del papel que las matronas debían desarrollar en la vida cotidiana ${ }^{2}$. Esencialmente debían ser madres y esposas y tener un lugar secundario, recatado y casto. En este artículo me propongo, por lo tanto, entender

1. Para más información sobre las acciones de estas mujeres excepcionales ver: Ortuño Pérez, 2016: 367-400; Masi, 2016: 209-236; Soto Chica, 2016: 251-286.

2. Suetonio (Aug. 64) nos informa de que Augusto promovía un comportamiento modesto entre las mujeres de su casa. cómo se fraguó el papel de estas mujeres, qué funciones pasaron a desarrollar y de qué manera se combinó su protagonismo con esa visión tradicionalista de la sociedad que se quiso imponer a inicios del Principado. Para ello realizaré un análisis de las principales actuaciones en la vida pública y política de las tres mujeres más cercanas al poder: Octavia, Livia y Julia.

\section{OCTAVIA}

Las mujeres fueron un elemento esencial en la política de Octavio/Augusto desde el momento en que se proyectaba su toma del poder en solitario. Cleopatra fue la excusa para declarar la guerra y esconder lo que realmente era un conflicto civil (DC 50.1.5; 50.20). Pero ya antes de la intervención de la reina egipcia, Octavia, la hermana de Octavio, había sido la moneda de cambio con la que sellar el pacto político entre este y Marco Antonio. La declaración de guerra fue seguida del divorcio de la hermana de Octavio (DC 50. 3.2.). A lo largo de la vida de Augusto las distintas mujeres de su familia ocuparán una posición substancial en la gestión de los asuntos paralelos a la política, pero la primera en actuar como un instrumento de poder fue Octavia.

Después de la muerte de su marido Marcelo en el 40 a. C., Octavia se casó con Marco Antonio, en un momento en el que se pretendía estrechar los lazos entre este y Octavio. Dion Casio (48.31.1) presenta este enlace forzado por el pueblo para conseguir el bien común. Cuando la situación dio un cambio radical, también lo hizo la relación de la pareja (Bauman, 1992: 92; Woodhull, 2003: 15-17). Las fuentes presentan a Octavia como la responsable del tratado de Tarento entre su hermano y su marido, el cual también se selló con otros matrimonios dinásticos de la siguiente generación (DC 48.54.4).

Tras este tratado, Marco Antonio habría hecho volver a Octavia a Italia (en los años anteriores ambos habían vivido en Atenas). La excusa fue que estaría más segura allí, mientras su marido se dirigía a la campaña pártica, aunque las fuentes transmiten que buscaba librarse de ella para continuar su relación con Cleopatra (DC 48.54.5; 49.33.4; 34.1). Para Octavio el asunto se volvió, necesariamente, de tipo personal. En la propaganda del momento se contrapuso la imagen de un hombre que había olvidado sus raíces romanas y se había aliado con una reina bárbara, a la de la pobre matrona abandonada a su suerte que, pese a todo, seguía haciéndose cargo de la casa, hijos, clientes y demás asuntos de su marido (DC 50.20.1; Plut. Ant. 54), epítome de la ideal mujer romana (Cortés Tovar, 2005: 199).

Octavio pudo exponer ante la opinión pública del momento que no solo estaba defendiendo la República de un hombre que había olvidado su romanidad, sino también a su hermana, una buena matrona, de la desidia de un marido que prefería a una reina oriental (DC 
50.20.1; 26.1-2). En el 35 a. C. Octavia habría convencido a su hermano para enviar refuerzos a Marco Antonio, pero, cuando se presentó en Atenas, no fue recibida por este ${ }^{3}$. Pese a la insistencia de Octavio, rehusó divorciarse y siguió administrando la casa de su marido como hasta ese momento. Sería Marco Antonio el que se divorciase de ella en el 32 a. C. (DC 50.3.2).

La posición de Octavia como buena mujer romana agraviada por su marido, que resultaba ser el enemigo de Octavio, hizo que esta se convirtiese en el centro de una campaña política de desprestigio contra Marco Antonio. Así, en el 35 a. C., a Octavia y Livia se les otorgó la erección de estatuas públicas, la libertad de tutela y la sacrosantidad igual a la del tribuno (DC 49.38.1 $)^{4}$. Hay autores que consideran que las dos primeras concesiones carecen de importancia (Bauman, 1992: 94), yo, en cambio, no lo entiendo así. Debemos tener en cuenta que hasta este momento las mujeres y los niños no eran retratados en estatuas públicas o monedas ${ }^{5}$. La primera mujer viva que pudo tener su efigie acuñada en una moneda fue, precisamente, Octavia tras su matrimonio con Marco Antonio (Bauman, 1992: 92; Woodhull, 2003: 15).

Las estatuas concedidas a mujeres eran un honor increíblemente raro y se conocen pocos; de los cuales, solo sobrevive la basa de la estatua de Cornelia, madre de los Graco (Plin. NH 34.31; Plut. Gai. Grac. 4; Severy, 2021: 27). La estatua de esta fue sufragada por el pueblo, mientras que la de Livia y Octavia lo fue por el Senado y, por lo tanto, una novedad en el momento (Flory, 1993: 287).

Los otros ejemplos de estatuas femeninas republicanas también destacan por ser representaciones de mujeres que con sus acciones habían ayudado de alguna manera al porvenir de la República. Las alusiones son literarias, no se conserva ningún tipo de resto material. Las mujeres honradas serían la vestal Taracia Gaia o Fufetia, mujer que entregó el Campo de Marte al pueblo romano (Plin. NH 34.25); Cloelia, quien ayudó a un grupo de romanos a escapar del cautiverio del rey etrusco Porsenna (Liv. 2.13.6-11), y Claudia Quinta, quien gracias a su virtud liberó una estatua de la Magna

3. Plutarco señala que en el momento en que Octavio permitió partir a Octavia en el 35 lo hizo no como un favor hacia ella, sino con la esperanza de que, si Marco Antonio la maltrataba, tendría base para un casus belli (Ant. 53.1).

4. No se sabe a través de qué tipo de procedimiento se concedieron estos honores pero, generalmente, se considera que debió de ser un decreto senatorial (Flory, 1993: 287).

5. Pese a que hacia el siglo I a. C. las referencias a los magistrados encargados de la acuñación y sus familias se hicieron cada vez más abundantes en los tipos monetarios, las alusiones a personajes femeninos que no fuesen deidades son extremadamente escasas. Cuando se incluían historias familiares en las acuñaciones se hacía en forma de referencia a los antecesores masculinos y las historias públicas de su casa. Solo Titurio Sabino incluyó mortales en sus acuñaciones al introducir a Tarpeya y a las Sabinas, permisibles por ser propias de época monárquica (Severy, 2010: 28; 223).
Mater que se había quedado encallada en el Tíber (Ov. Fasti 4.305-344; Val. Max.1.8.11; Tac. Ann. 4.64.5). Desde la estatua de Cornelia hasta las de Octavia y Livia no hay más testimonios de imágenes públicas concedidas a mujeres (Flory, 1993: 288-290; Barret, 2004: 204).

La erección de estatuas era un honor dirigido a hombres que habían ganado triunfos, logrado grandes hazañas, efectuado actos de munificencia o salvado vidas de ciudadanos. Las historias de estas mujeres republicanas se igualaban, a través del honor de la estatua, a estos sacrificios y grandes actos en nombre de la República. La erección de imágenes públicas para la esposa y hermana de Octavio, quienes no habían realizado labores comparables a las de las mujeres anteriores, era, por lo tanto, un gran honor concedido por su posición de «mujeres de» y que se ensalzó aún más al ir acompañado por otros privilegios. Al mismo tiempo, marcará la introducción de imágenes de los miembros femeninos de la casa imperial como un nuevo elemento de la política y la propaganda ${ }^{6}$ (Flory, 1993: 291-296; Bartman, 1999; 2012; Wood, 1999).

Por su parte, la liberación de la tutela supone un claro paso adelante en la guerra de propaganda del momento. Ante los ataques y vejaciones de Marco Antonio hacia Octavia, esta última conseguía, por decisión del Senado, la liberación total del sometimiento a la tutela de su marido. De manera pública se reconocía que las acciones de Marco Antonio eran perjudiciales, aunque se encuadrasen en la esfera de lo privado.

Por último, la sacrosanctitas tribunicia fue otorgada por primera vez a dos mujeres (Scardigli, 1982). Recibían, de esta forma, un privilegio propio de un cargo público. Purcell (1986: 86) sostiene que con la concesión de la protección se estaba animando a Livia y Octavia a asumir un cierto rol público, ya que aquellos que ejercían funciones públicas necesitaban algún tipo de protección especial. Aunque ambas mujeres fueron desarrollando con el paso del tiempo tareas cada vez más relacionadas con la escena pública, no creo que se pueda afirmar que este fuese el motivo o, en todo caso, el único, para esta concesión en un momento tan temprano como el 35 a. C. Desde el fin de la guerra con Marco Antonio y Cleopatra en el 31 a. C. y hasta la erección del Ara Pacis en el 12 a. C. no volvemos a ver honores de semejante calado dirigidos a las mujeres imperiales.

En mi opinión, la obtención de la sacrosanctitas tribunicia debe leerse en la misma línea que la liberación de la tutela masculina. Con el objeto de proteger a Octavia de los ataques de Marco Antonio se les

6. La erección de estas imágenes públicas es significativa por ser estas las primeras de una larga serie y por lo temprano del momento. Lógicamente, este tipo de honores, incluyendo estatuas e inscripciones, se extenderán a lo largo de las vidas de estas mujeres e incluso después, tanto en Roma como en otras ciudades del Imperio (Marengo, 2008). 
concedía a ambas mujeres una posición sin precedentes. Debemos tener en cuenta que se les podría haber propuesto la sacrosantidad de las vestales $\mathrm{y}$, sin embargo, se les ofreció la de los tribunos pese a no ser y nunca poder llegar a ser tribunos (Bauman, 1992: 94), situándolas en una posición de extrema relevancia ${ }^{7}$. En este contexto parece que los honores otorgados se dirigían a reforzar la condena del pueblo romano hacia Marco Antonio, culpable del maltrato que recibía Octavia. Livia, al ser la mujer de Octavio, no podía quedar fuera, de manera que participó de los honores, pero de forma secundaria (Flory, 1993: 293-294; Barret, 2004: 214).

No podemos estar seguros de la imagen que las fuentes transmiten sobre Octavia, pero, en cualquier caso, la concesión de estos honores a las mujeres de la familia de Octavio expresa la destacada posición que se les confirió en los asuntos políticos del momento ${ }^{8}$. Con sus acciones durante el Triunvirato, Octavia aparece en las fuentes como la heredera de las grandes mujeres de finales de la República, como pueden ser Julia, mujer de Pompeyo; Aurelia, madre de César; Servilia o Fulvia. Estas son retratadas en un segundo plano, manejando a su manera los acontecimientos en favor de sus familias. Pese a ser herederas de estas matronas, en el Principado, la posición de las mujeres tomará un carácter mucho más oficial con un tipo de reconocimiento público que contaba con pocos precedentes.

Octavia mostrará una imagen más discreta tras la derrota de Marco Antonio y el inicio del Principado, siempre relacionada con su capacidad de producir herederos y como cuidadora y educadora de niños. Así, tras el fin de las guerras, la principal generación de niños julio-claudios se educará en su casa, donde acogió, además de a sus propios hijos, a los de Marco Antonio de sus matrimonios con Fulvia y con Cleopatra (DC 51.17.7). Marcelo, el único hijo varón de su primer matrimonio, será el primer elegido como sucesor de Augusto. Pero sus hijas también tendrán un papel destacado en el momento y a lo largo de la dinastía julio-claudia. Así, ante la falta de herederos directos

7. No obstante, Bauman sostiene que la santidad de las vestales no era suficiente a ojos de Octavio, ya que solo servía para proteger en caso de ataques locales, no como pretexto para iniciar una guerra (Bauman, 1992: 97).

8. Podemos dudar de los relatos de Dion y Plutarco sobre la influencia de Octavia en el tratado de Tarento, ya que sería aceptar la práctica nulidad política de Marco Antonio, que no habría tenido un papel activo en las negociaciones (Singer, 1947: 174). También es posible que la situación posterior de Octavia, quedándose en casa y cuidando de los niños de Marco Antonio, fuese exagerada por la propaganda de la época para exaltar su posición como la matrona ideal en comparación con Cleopatra (Fischler, 1994: 118). De una forma muy parecida también Plutarco se compadece de Fulvia (Ant. 28), defendiendo en Roma los intereses de su marido, mientras este se encontraba con Cleopatra. Pese a lo criticada que es por muchos autores, a Fulvia se la presenta prácticamente igual que a Octavia como víctima y elemento necesario para destacar la mala actuación de Marco Antonio (Gafforini, 1994). de Augusto, las hijas de Octavia fueron utilizadas para forjar alianzas (Cid López, 2016: 307-330). Octavia será la abuela de Mesalina a través de Marcela la Mayor; bisabuela de Nerón a partir de su hija Antonia la Mayor, y por Antonia la Menor, bisabuela de Calígula y abuela de Claudio. Por tanto, Octavia se relaciona, mediante sus hijas, con las diferentes generaciones de la dinastía.

Tras el divorcio de Marco Antonio, sin embargo, no se volverá a casar. Pese a que las fuentes dejan de lado su persona tras Accio, con semejante descendencia parece claro que su influencia en la familia de Augusto debió ser importante. Hasta tal punto lo habría sido, que ciertos autores señalan que Augusto le pidió que permitiese a su yerno Agripa divorciarse de su hija, Marcela, para casarse con Julia (Suet. Aug. 63).

$\mathrm{Su}$ relevancia en la vida pública y la intención de halagar a Augusto fueron tales que a su muerte se le ofreció un funeral público e incluso los senadores guardaron luto. El funeral público había estado reservado durante la República a los hombres (Severy, 2010: 27-28), por lo que fue concebido como un gran honor en sí $^{9}$. A mayores se hicieron otras proposiciones para honrar su memoria y a Augusto. Estos honores nos son desconocidos, pero debieron ser múltiples e importantes pues se dice que el emperador rechazó muchos (DC 54.35.4). La importancia de la hermana de Augusto será exaltada por las generaciones venideras, normalmente con la intención de expresar una clara conexión en líneas ascendente con Augusto, como sucede en el caso de Claudio ${ }^{10}$.

\section{LIVIA}

La importancia de Octavia durante el periodo triunviral es, como vimos, esencial. Sin embargo, en el periodo que sigue la presencia pública de las mujeres decae.

9. Severy (2010: 94) también sostiene que fue el gran funeral de Octavia, con honores nunca antes tributados a una mujer y su carácter público, lo que sentó las bases y marcó el inicio del papel público de las mujeres imperiales, que se reforzaría con los honores tributados a Livia a partir del 9 a. C. Cenerini (2016: 30-31) afirma que el funus de Marcelo y el de Agripa tuvieron gran importancia en la definición de la domus Augusta, al convertirse en un momento y lugar privilegiado de formación del consenso sobre el progresivo reconocimiento de la casa imperial. Con Octavia se inauguran los funera femeninos que también contribuyen a la creación de la dinastía de los julio-claudios.

10. Claudio era nieto de Octavia a través de su madre Antonia la Menor. Su esposa Mesalina también era descendiente de Octavia tanto por vía materna como paterna. Solo así se explica que sus hijas llevasen nombres que hacían referencia a la ascendencia femenina. Esto era una rareza en Roma, donde las mujeres heredaban nomen y cognomen de su padre. La costumbre solo empezará a cambiar a partir del Principado, sobre todo en época flavia (Kajava, 1972; Kajanto, 1994). 
En el 19 a. C. Augusto inicia la legislación destinada a paliar los excesos que habían dado lugar a la crisis moral causante del periodo de guerras (Suet. Aug. 34.1). Estas leyes se inmiscuyeron en asuntos que hasta ese momento habían quedado bajo la jurisdicción del paterfamilias; lo cual, por un lado, situaba a Augusto como un padre a la cabeza de la comunidad y, al mismo tiempo, sentaba las bases sobre cómo debían comportarse las mujeres de su familia. Las normas suntuarias y sobre el matrimonio afectaban tanto a hombres como a mujeres, pero en el caso de estas últimas estaban dirigidas a reimplantar el modelo de la casta matrona republicana; ya defendido por Octavia durante el triunvirato y al cual debían ceñirse todas las mujeres de su familia ${ }^{11}$. En este contexto debemos situar las escasas noticias que tenemos de Livia y del resto de las mujeres de la familia ${ }^{12}$ hasta el año 9 a. C., cuando Livia vuelve a obtener honores del Senado como consolación a la muerte de su hijo Druso (DC 55.2.5).

11. La Lex Iulia de maritandis ordinibus se dirigió a establecer privilegios para hombres y mujeres con más de tres hijos, así como los periodos máximos que podían pasar desde un divorcio o viudez hasta el siguiente matrimonio. Se prohibió que los celibes recibiesen herencias excepto de un pequeño círculo de su familia más cercana. Las mujeres solteras o sin hijos fueron castigadas de la misma manera. Aunque hay varias teorías al respecto, parece que en el momento se justificó por la necesidad de aumentar la población y estas leyes acabaron afectando tanto a los romanos de época de Augusto como de generaciones posteriores (Balsdon, 1983: 76-77; Tregiari, 1991: 60). La lex Iulia de adulteriis coercendis hacía que la jurisdicción sobre el adulterio pasase de las manos de la familia al Estado, siendo el destierro el castigo normal para ambas partes. El marido debía divorciarse de su mujer ante testigos; después podía presentar sus alegatos. Si el marido decidía no actuar en contra de su mujer, se permitía que cualquier ciudadano, mayor de veinticinco años, lo hiciese en su lugar. El marido también podía ser castigado si se demostraba que estaba al tanto de las infidelidades, pero aun así no había hecho nada al respecto. Ante las protestas generalizadas, sobre todo en los círculos senatoriales, en el año 9 a. C., se introdujeron algunas enmiendas, con el nombre de lex Papia Poppaea, que suavizaron estas dos leyes. En todo caso, Augusto convirtió a la familia en una institución bajo la protección del Estado y a través de las penalizaciones buscó retornar a la percepción de la familia como una unión destinada a la procreación de niños (Balsdon, 1983: 77-78).

12. Sorprende, sobre todo, en el contexto de los Ludi Saeculares. En este festival tuvieron cierta relevancia las matronas senatoriales que participaron, durante tres noches consecutivas, encargándose de las ofrendas a Juno y Diana y cantando el himno a Juno Regina. Aunque tradicionalmente se ha supuesto que algunas de las mujeres de la casa imperial tuvieron que participar en estos actos (Fantham, 2006: 61), las fuentes antiguas no lo reflejan. Resulta curioso que los cronistas de la época no señalen la presencia de las mujeres de la casa de Augusto en un acto concebido como el gran culmen de la restauración moral; gran obra ideada de cara a clausurar definitivamente el periodo de guerras e iniciar una nueva etapa (Zanker, 1992: 202-208).
Sin embargo, aunque de forma más indirecta, su presencia desde época triunviral parece haber sido esencial para la configuración del poder de Octavio. Si los vínculos matrimoniales eran importantes en la Roma republicana como medio para forjar alianzas políticas, no lo fueron menos en el caso del matrimonio de Octavio y Livia. Esta parece haber granjeado a su nuevo marido un mayor grado de aceptación entre la nobleza senatorial dada su pertenencia a dos grandes líneas, como la de los Claudios y la de los Livios Drusos (Barret, 2004: 22). La importancia política de la unión explicaría que en el momento el matrimonio fuese aprobado pese a estar la novia embarazada de su anterior marido (Tac. Ann. 1.10.5).

Aunque se mantuvo en la sombra hasta el año 9 a. C., la posición que Livia llegará a ocupar y la imagen que desarrolla son un precedente para todas las emperatrices posteriores. Livia tendrá un estatus y alcanzará riquezas y privilegios nunca antes vistos para una mujer.

No obstante, es difícil seguir su trayectoria teniendo en cuenta las afirmaciones de las fuentes. Livia, junto a otras mujeres fuertes que la sucederán, recibieron un trato desfavorable por parte de muchos escritores antiguos (Cid López, 2014: 180), por no mencionar la leyenda negra que rodea a toda la familia julio-claudia que, durante siglos, no recibió ningún tipo de juicio crítico. En la actualidad, mientras que de alguna manera se ha intentado «desdemonizar» a figuras tan controvertidas como Calígula o Nerón, solo se han dado los primeros pasos para tratar con el mismo rigor a los personajes femeninos, víctimas de la misoginia tanto antigua como contemporánea. Si nos ceñimos a las palabras de los autores antiguos sobre las grandes matronae augustas, resulta complicado diferenciar los hechos reales de los inventados con la intención de atacar a los personajes femeninos de la historia. En mi estudio intentaré apartarme de los comentarios más polémicos que han encontrado eco en tesis actuales, aplicando el mismo cuidado que algunos célebres historiadores han empleado a la hora de hablar de controvertidas figuras masculinas, ya mencionadas, y poniendo especial énfasis en la lectura crítica y en la depuración de la imagen.

Así pues, la importancia de Livia radica en su posición como mujer del emperador y madre del siguiente príncipe. En su último papel se encuentran la mayoría de las críticas, ya que los autores de la época entendían que había sido Livia quien había impuesto a su hijo como sucesor de Augusto (Tac. Ann. 1.5.4; 4.57.4; DC 56.30.1; 56.12; 57.3.3; Suet. Tib. 21.2). Más allá de esta cuestión, como mujer del emperador y al sobrevivirle durante bastantes años, su influencia sobre los asuntos de la época debió de ser notable.

En primer lugar, su nombre aparece también relacionado con algunos curiosos omina imperii. El más conocido es probablemente el relativo a su finca llamada Ad gallinas albas. Según Suetonio (Tib. 14.1; Gal.1), estando Livia en el campo, un águila habría dejado caer una gallina blanca con una gran cresta y una 
rama de laurel en el pico en su regazo. Livia la habría criado en su finca. Las gallinas blancas se multiplicaron y la finca pasó a ser conocida por este hecho. Por otro lado, plantó el laurel, que creció y se multiplicó y los emperadores de la familia julio-claudia lo utilizaron para sus coronas del triunfo. A través de los polluelos que representaban a los emperadores se reconocía la figura de Livia como matriarca de la familia, reafirmada en su relación con el laurel del triunfo. Cuando la dinastía cayó, también desaparecieron las gallinas y los laureles.

En su función de mujer de Augusto, Livia lo habría aconsejado. Como reflejan los autores antiguos, sus opiniones debieron de tener tal calado en su marido que este anotaba sus pensamientos antes de ver a su esposa para poder comentárselos con más claridad (Suet. Aug. 84). Por su parte, Dion afirma, en un discurso inventado, que Livia tuvo una gran influencia como consejera de su marido ante la indecisión de este sobre cómo actuar tras la supuesta conjura de Cinna (55.1521). También le habría acompañado en sus viajes por el Imperio. Un discurso de Druso en el Senado donde planteaba que debía permitirse a las mujeres de los gobernadores viajar con sus maridos, así lo demuestra (Tac. Ann. 3.35.6). A la muerte de Octavia puede que recibiese alguna de las responsabilidades de esta, como la del cuidado de los niños de la corte (Dennison, 2010). Por las cartas entre Augusto y Livia que refleja Suetonio nos enteramos de que Claudio parece haber estado al cuidado de Livia ${ }^{13}$ (Clau. 4.1-5). Además, al afirmar Augusto que si Livia «así lo desea» puede enseñarle una carta a Antonia en la cual trataban ciertos asuntos sobre el futuro del muchacho, parece que era la abuela quien tenía la última palabra a la hora de tomar decisiones sobre el nieto ${ }^{14}$ (Barret, 2004: 190). Sabemos que Calígula vivió un tiempo con ella (Suet. Cal. 10.1) y que Galba, a quien quiso dejar parte de su herencia, fue su favorito durante la infancia (Suet. Gal. 5.2). También Otón, abuelo del futuro emperador, se crió en su casa y llegó a pretor gracias a su influencia (Suet. Oto. 1).

Su papel como madre fue considerado tan relevante que cuando en el 9 a. C. murió Druso, Livia recibió por parte del Senado algunos honores con la intención de consolarla por su pérdida (Salazar Revuelta, 2016: 358-359). Entre estos se encontraba una nueva estatua pública, pero también el ius trius liberorum (DC 55.2.5), que le otorgaba todos los beneficios de las mujeres que habían tenido tres hijos. Entre estos se

13. Antonia, a la muerte de Druso, se trasladó con Livia y no se volvió a casar, por lo que no extraña que también Claudio viviese con ellas (Val. Max. 4.3.3).

14. Antonia habría sido otra de las mujeres que compartirían las responsabilidades de la crianza de los niños tras la muerte de Octavia. En su caso destacan las buenas relaciones con reyes clientes, a cuyos hijos habría criado en su casa, dando pie a que Calígula (quien también fue educado por ella) heredase esos buenos vínculos (Jos. AJ 18.143; 156; 164-7; 179-86; 2.178; 181-183). encontraba la posibilidad de heredar y dejar legados, un avance considerable en su estatus. Livia solo había tenido dos hijos, pero con esta concesión se reconocía que su labor como madre y el valor de sus hijos habían sido tan importantes para la República como si estos hubiesen sido tres. Antes señalaba que el honor de una imagen pública estaba reservado para hombres que hubiesen hecho grandes esfuerzos por el bien de la República. A través de estos honores se reconocía que el bien que Livia había aportado a la República era su hijo, por lo que merecía reconocimiento público (Flory, 1993: 297-300).

Unos años antes, en el 12 a. C. se había consagrado el Ara Pacis el 30 de enero (Ov. Fasti 1.710-722), día del cumpleaños de Livia. Año tras año, se harían sacrificios públicos en esta fecha tan señalada, aunque fuese por un motivo distinto al natalicio de la esposa de Augusto. Asimismo, en este monumento aparecen retratados la gran mayoría de integrantes de la familia imperial ${ }^{15}$. Ya señalé que en época republicana no se solía retratar a mujeres y niños, por lo que el Ara Pacis marca la completa ruptura de esa tradición. A ello se suma la nueva estatua concedida en el 9 a. C. Las imágenes de las mujeres imperiales entraban, de esta forma, en los contextos públicos (DC 55.2.5).

Las fuentes nos transmiten, además, un elemento que puede ser una de las características principales de las damas de la corte a la hora de complementar el poder del emperador, su capacidad como intermediarias o benefactoras. A lo largo del Imperio será corriente que los emperadores concedan favores a los individuos de las capas más altas de la sociedad como patronos. Los parientes próximos, debido a su cercanía al princeps, emanaban su poder e influencia (Barret, 2004: 275276; Paterson, 2007: 129 y 141). Ya en la República las mujeres tenían capacidad para expresar su parecer sobre los asuntos familiares. Las opiniones de las matronas debían ser educadamente tenidas en cuenta y era parte de la autoridad que estas desarrollaban dentro de la casa. Esto tiene especial relevancia en el caso de las mujeres imperiales, ya que su casa era la casa imperial y su paterfamilias el emperador ${ }^{16}$. La influencia de la mujer romana sobre su hogar fue, por lo tanto, uno de los elementos principales en el desarrollo del papel y poder de la mujer imperial (Fischler, 1994: 122-123; Hallet, 2012: 374; Salazar Revuelta, 2016: 331-364).

Ciertamente, las mujeres de la corte, gracias a su mayor influencia y a sus grandes riquezas pudieron

15. No solo aparecen representaciones de los familiares vivos en ese momento. En el Ara Pacis todas las alusiones que se hacen a la religión, la procesión, el sacrificio, la paz, la abundancia, etc. aparecen ejemplificadas a través de representaciones de la familia tanto humana como divina (Zanker, 1992: 208-230; 239-246; Severy, 2010: 104-112)

16. Así por ejemplo, sabemos que Augusto intercambiaba cartas con las mujeres de su familia que, de esta forma, le harían saber su parecer sobre diversos temas (López y Pociña, 2019: 210). 
beneficiar a muchos individuos y colectividades ${ }^{17}$. Las ricas mujeres aristocráticas ya actuaban como patronas en época republicana, pero ahora la fortuna de la familia permitió que las obras y actos benéficos que estas acometieron fuesen más significativos ${ }^{18}$. Sus intervenciones fueron, bien a través de la mediación de sus parientes masculinos, bien directas. Octavia, durante el triunvirato, ya había intercedido en nombre de algún proscrito y de los socios de su marido ante su hermano (DC 47.7.4-5; Plut. Ant. 35.2; 54). En el caso de Livia se pueden citar algunos ejemplos; la mayoría en las obras literarias, sabemos que ayudó a las familias desfavorecidas y que dio dotes a muchas hijas de senadores ${ }^{19}$. Dion afirma que también salvó las vidas de muchos hombres (58.2.3). Utilizó su riqueza para ayudar y extendió la red de clientela de la casa imperial.

Suetonio (Aug. 40.3) la retrata intercediendo en nombre de un galo tributario directamente ante Augusto, con la intención de conseguirle la ciudadanía. Aunque Augusto se la denegó, en su lugar logró la liberación de la obligación de pagar tributo. También intercedió para conseguir la ciudadanía para Samos como se refleja en la carta que envió Augusto al pueblo denegando este derecho y afirmando que su esposa había abogado en su favor (Reynolds, B.270, n. ${ }^{\circ} 13$, línea 5).

$\mathrm{Al}$ igual que el propio emperador concedía beneficios a individuos y comunidades ${ }^{20}$, los testimonios sobre Livia demuestran que las mujeres de la familia tenían capacidad para ayudar o, en todo caso, para interceder en su nombre ante el emperador. En la misma línea, Veleyo afirma que Livia nunca utilizó su influencia más que para ayudar a los demás (2.130.4). Las menciones de Ovidio a Livia en su obra escrita durante el destierro se encuadran dentro de este contexto, ya que el poeta entendía que si alababa a la mujer del emperador, esta podría defender su causa ante su

17. Hidalgo de la Vega (2012) sostiene a este respecto que, en los casos de Octavia y Livia, al ser liberadas de la tutela masculina en el 35 a. C., pudieron disponer de fondos propios con los cuales ayudar a los menos favorecidos. No tenemos pruebas de que este tipo de privilegios fuesen extendidos al resto de mujeres imperiales a lo largo del Principado. Sin embargo, las mujeres de la domus Augusta, siguiendo el modelo de sus antecesoras, mantuvieron la labor caritativa que complementaba a las políticas imperiales.

18. Para hacernos una idea de las riquezas de estas mujeres solo hay que tener en cuenta que las propiedades que compartían Livia y Tiberio en la Narbonense fueron tan extensas que necesitaron de un procurador específico para ellas (Pflaum, 1960-1961: n.13).

19. Los ejemplos presentes en las fuentes epigráficas son menos numerosos. Algunos ejemplos: ILS 8897; IGR 4.73; 1.835.

20. Podemos citar el caso de Hórtalo, descendiente de Hortensio, a quien Augusto había concedido una suma de dinero para que pudiese formar una familia y hacer que el linaje del orador no desapareciese. Tras la muerte de Augusto, se dirigió a Tiberio para solicitar que continuase el beneficio (Tac. Ann. 2.37.2). marido (Trist. 1.6.25-27; 2.161-164; Pont. 3.1.114.118; $3.125-128$; 3.139-142; 14.56).

Otro ejemplo de la posición pública que se intentó promover tanto para Livia como para Octavia está en las obras arquitectónicas que ambas impulsaron. Octavia no solo ayudó al arquitecto Vitrubio (Arch. 1), sino que ella misma parece haber sufragado un edificio en el Campo de Marte, espacio que Agripa y Augusto se disponían a reorganizar con edificios que hiciesen referencia a la familia Julia (Woodhull, 2003: 20). Livia se ocupó, de forma paralela a su marido, de la reforma de templos; en su caso, aquellos relacionados con valores propios del mundo femenino, como el templo de Bona Dea (Ov. Fasti 148-158) o Fortuna Muliebris (CIL 6. 883). Pero el edificio sobre el que más datos tenemos es la porticus Liviae que, además, contaba con una aedes a Concordia en su interior (Ov. Fasti 6.635). El patronazgo arquitectónico de estas mujeres ha sido interpretado como una extensión de su papel dentro del nuevo sistema (Woodhull, 2003: 23).

Al mismo tiempo, el acto de dedicación del templo debió de ser un evento público en el que aparecían Livia y Tiberio ante la multitud. Livia se presenta en público acompañada de su hijo $\mathrm{y}$, de alguna manera, ambos ejercían como representantes de Augusto. Las mujeres pasan a tener un papel en la vida cotidiana de la ciudad y vemos también que Livia ofrecía banquetes a las mujeres del Senado (DC 54.2.4) o acudía a los juegos (Mac. Sat. 2.5.6).

La porticus Liviae y la porticus Octaviae parecen haber sido colaboraciones entre madre e hijo ${ }^{21}$. Marcelo, siendo en ese momento posible heredero de Augusto, habría apoyado a Octavia en la obra arquitectónica que ofreció a la ciudad (Ov. Ars. Am. 1.69-70). Las referencias a Marcelo en el monumento se habrían potenciado después de su trágica muerte. En el caso de la porticus Liviae, este fue dedicado junto a Tiberio y se piensa que el acto pudo tener lugar el 17 de enero del 7 a. C., fecha del aniversario de bodas de Livia y Augusto. Podemos interpretarlo como muestra de apoyo y cercanía entre Livia y Tiberio, sobre todo tras la muerte de Druso (Flory, 1984: 309-311).

Tiberio no participó en la construcción de la aedes a Concordia, aunque, por su parte, reformó el templo de Concordia en su nombre y el de su hermano (Ov. Fasti 1.636-649; Suet. Tib. 20). Las múltiples referencias a Concordia han hecho que se discuta sobre la intencionalidad del altar sufragado por Livia. Flory (1984) lo interpreta, dentro del conjunto de obras patrocinadas

21. Estas habrían sido construcciones que conservaron un gran valor simbólico con el paso de las dinastías. En el caso de la porticus Octaviae, Septimio Severo se dedicó a su restauración con la intención de dar propaganda a su imagen imperial y a la familia dentro de esta. Además de promover su propia persona, la restauración permitía a Severo establecer vínculos con aquellos que las habían erigido en un primer momento (Gorrie, 2007). 
por Livia, como un elemento más que alude al comportamiento adecuado en una matrona ${ }^{22}$.

Sin embargo, en el contexto de la época, entiendo que se le puede dar otro significado. La implicación de Tiberio en la edificación impulsada por su madre me parece elemental si tenemos en cuenta que en la porticus Octaviae había participado Marcelo. Ambos fueron yernos de Augusto y personajes eminentes en el Imperio. Sus intervenciones en estos ámbitos junto a sus madres se pueden interpretar como un gesto de apoyo de estas hacia sus hijos (en este sentido: Woodhull, 2003: 24-25). Livia habría añadido la aedes a Concordia para reforzar la vinculación con su hijo.

Por otro lado, la alusión general a Concordia también puede indicar que esta no hacía referencia a un individuo en particular, sino que invocaba las buenas relaciones entre Tiberio y Augusto, entre Augusto y Livia, entre Tiberio y Cayo y Lucio, etc. En una domus formada con retales de distintas familias, ciertamente la Concordia debió de ser un elemento propicio de cara a fortalecerla y promover las buenas relaciones. No obstante, la imagen que nos ha llegado a través de las fuentes es completamente contraria, con continuas referencias a las desavenencias entre Julia y Tiberio o entre este y sus hijastros. Aunque no podemos trazar la fiabilidad de estas alusiones de la prensa amarilla de la época, es posible que desde fuera de la domus se hubiese entendido que una familia así podría tener problemas internos. En este sentido, Livia como cabeza femenina de la familia, habría invocado a esta deidad con la intención de mostrar que todo iba bien de puertas adentro de su casa.

El espacio de los pórticos en sí también debe ser tenido en cuenta. Estos proporcionaban un ámbito que podía ser disfrutado por el conjunto de la población romana. En el caso de la porticus Liviae, este se encontraba en el Esquilino, en la zona de la Subura, y los habitantes, habituados a callejuelas estrechas y oscuras, súbitamente recibían la posibilidad de pasear por un entorno magnífico repleto de obras de arte y luz, disfrutando del aire limpio, las fuentes y los jardines. La porticus Octaviae ofrecía las mismas posibilidades, pero al encuadrarse en el Campo de Marte estaba demasiado lejos para ser disfrutado por la población (Zanker, 1992: 169-170). A través de sus obras, las mujeres de

22. La autora se basa en que el tipo de construcciones sufragadas por Livia, como los ya mencionados templos de Bona Dea o Fortuna Muliebris, están siempre relacionados con las funciones y los valores típicamente femeninos. Además, el día en que Ovidio (Fasti 6.475-570) sitúa la dedicación del altar a Concordia, el 11 de junio, se celebraba también el festival de Matralia en honor de Mater Matuta. El mismo día también era la festividad de Fortuna Virgo y, poco antes, el 9 de junio, se celebraba Vestalia. Flory (1984: 314) destaca, por lo tanto, la cantidad de fechas relacionadas con ritos religiosos en torno a las madres y a la vida familiar como un intento de situar a Livia como el epítome de estos valores dentro de la nueva política moral y familiar de Augusto. la familia optaban por favorecer el bienestar común en lugar de la ostentación privada. En esa misma línea, las fuentes aluden a la sencillez tanto de Octavia como de Livia (DC 58.2.5).

Estas acciones se situarían en el contexto de la legislación de Augusto contra el lujo privado. Esta motivación está mucho más clara en el caso de la porticus Liviae, construido sobre la antigua mansión de Vedio Polión. Este hombre rico, amigo de Augusto, había dejado a su muerte grandes posesiones al príncipe. Augusto, en lugar de mantener para uso privado la villa de Roma, decidió derruirla y allí Livia construyó su porticus (DC 54.23). La intención fue atacar la ostentación privada, pese a la pérdida material que ello suponía para Augusto, y ofrecer un lugar de esparcimiento para toda la población. Agripa, por ejemplo, había dejado en su testamento gran parte de sus posesiones en Roma a la ciudadanía y sus construcciones se habían centrado en mejorar la vida de los romanos (DC 53.23.1-3; 23.27.1-3; 54.11.7).

En su calidad de primeras mujeres de Roma y familiares de Augusto, Livia y Octavia realizaron un tipo de contribuciones que ensalzaban la ideología del nuevo régimen (Cenerini, 2016: 27). Con sus acciones complementaron, igual que los hombres de la familia, las obras de Augusto y representaron a este allá donde fueron. La presencia del emperador se hacía más patente y llegaba a mayor cantidad de población gracias a la ayuda de sus mujeres. Sus actos como patronas e intercesoras hicieron que ocupasen un lugar vital a la hora de asegurar que los amplios estratos de la sociedad romana se ligasen a la estrecha élite alrededor de Augusto (Flory, 1984: 319-320; Purcell, 1986: 86; Woodhull, 2003: 25). El príncipe ciertamente estaba demasiado ocupado como para asistir a todos los actos y tratar con todos aquellos que solicitaban su ayuda y su favor, pero, a través del trabajo de sus mujeres, se hacía presente en mayor número de escenarios.

Como ya mencioné, la posición de Livia durante el gobierno de Augusto se diferencia con respecto a la de las mujeres republicanas en que es más constante y sistemática (al menos tras el 9 a. C.), siempre presente como apoyo de su marido y de su hijo. Severy (2010: 31) señaló que, si bien se puede encontrar un precedente para las acciones de las mujeres imperiales en las matronas senatoriales de los dos últimos siglos de la República, el gran cambio se encuentra en la aceptación y promoción de su reconocimiento público y su conmemoración. Livia tiene un rol público que, si bien no incluye ningún tipo de poder oficial, complementa el papel de su marido, se relaciona con la población y difunde el mensaje que Augusto quería transmitir. Su función también es importante en el sentido tradicional e intervendría en favor de sus vínculos clientelares, pero, definitivamente, crea una función nueva, la de mujer del emperador, que completaba su papel.

Aun así, no es en este momento cuando desarrolla su pleno potencial como emperatriz. Fue tras la muerte de Augusto cuando se reveló en su testamento el lugar 
de extrema relevancia que dejaba a su viuda. Al ser adoptada dentro de la familia Julia tomó el nombre de Iulia Augusta ${ }^{23}$ y fue la principal beneficiaria de los legados económicos de Augusto (junto a Tiberio), aumentando su nada desdeñable fortuna ${ }^{24}$, y que, de seguro, le permitieron potenciar los actos benéficos que llevó a cabo durante el gobierno de su hijo (DC 56.46; Tac. Ann. 1.8). Otros elementos, como su posición de flaminica del divino Augusto llegarán también en ese periodo y quedan, por lo tanto, fuera de mi estudio (Tac. Ann. 1.14.2; Grether, 1946; Frei-Stolba, 2008). En todo caso, conviene señalar que, pese a la posición elevada que Augusto concibió para las mujeres de su familia, esta estuvo siempre encuadrada en la tradición y que fue solo tras su muerte cuando se experimentó con un papel femenino que fuese completamente nuevo.

\section{JULIA}

Volviendo atrás en la historia ya señalé que la entrada de Octavio en la vida pública estuvo marcada por ciertos matrimonios con tendencias políticas. Así, las dos esposas que este llegó a tener antes de Livia son notables por sus conexiones familiares. Primero se prometió con Servilia, hija de Publio Servilio Isáurico, relacionándose por matrimonio con Bruto, Casio y Lépido. No llegó a oficializarse el enlace, ya que cuando se reconcilió con Marco Antonio, la alianza se selló con el compromiso de Octavio y la hijastra de este a través de su mujer Fulvia, Claudia (hija también de Publio Clodio) (Plut. Ant. 20; DC 46.56.3). Los problemas que Octavio tuvo con Fulvia pusieron fin al enlace (DC 48.5.3). En el 40 a. C. se casó con Escribonia, quien era hermana del suegro de Sexto Pompeyo y ya tenía varios hijos propios (Barret, 2004: 22). De esta se divorciará en cuanto dé a luz a Julia (DC 48.34.3).

Esta tendencia a usar a las mujeres para forjar alianzas era bien conocida en la República y la casa imperial que, en sus primeros momentos, funcionaba al modo republicano, mantendrá la costumbre. El ejemplo paradigmático es el de Julia, única hija de Augusto. Si Octavia fue un elemento clave en la propaganda de Augusto y Livia su representante allí donde fuese, la función de Julia fue la de proveer de herederos a la familia y forjar alianzas políticas. Aparentemente, Augusto entendía que la sucesión en el poder imperial sería más fácil si conseguía transmitirse dentro de la familia y, al no tener hijos propios, se sirvió de las

23. No hay precedentes sobre la asunción por parte de una mujer de un cognomen honorífico de un miembro de la familia (Flory, 1997: 113). Es, precisamente, este apodo el que acabe institucionalizándose como título oficioso de las emperatrices, tanto para el periodo julio-claudio como posteriores.

24. Para lo que tuvo que ser eximida del cumplimiento de la lex Voconia que limitaba las herencias que podían recibir las mujeres (DC 56.32.1). mujeres de su familia. De ahí los sucesivos matrimonios de Julia (Hidalgo de la Vega, 2003: 52; Cid López, 2018: 138).

En primer lugar, fue prometida, cuando todavía era una niña, a Antilo, hijo de Marco Antonio, en el marco de los acuerdos de Tarento (DC 51.15.5-7; Suet. Aug. 56.2). Sus matrimonios, primero con Marcelo y luego con Agripa, tenían intenciones más claramente dinásticas (DC 54.6.5; Rodríguez López, 2016: 442). Con el enlace con Marcelo cerraba el vínculo familiar de su primo/esposo con su padre, quien habría ejercido como sucesor de no haber muerto prematuramente. Por otro lado, si Julia se hubiese casado con otro hombre, este habría tenido una posición privilegiada, mientras que Marcelo, al ser el familiar varón más cercano de Augusto, podría haber optado igualmente a la sucesión. Al casarlo con Julia evitaba las posibilidades de conflicto creando una única línea.

Las decisiones de Augusto respecto a Julia revelan que el emperador era consciente de la importancia que ella iba a tener en el seno de la dinastía, al reforzar la línea familiar en la sucesión, y en la propaganda del momento (Domínguez Arranz, 2010: 155-156). Cualquier descendiente de Julia lo sería también de Augusto y, a través de él, del divino Julio. En el mundo romano el papel de la mujer como madre y esposa era esencial; en el caso de Julia, esas facetas tomaron nuevas dimensiones relacionadas con la supervivencia del nuevo sistema.

El siguiente matrimonio de Julia, en este caso con Agripa, tenía la doble finalidad de proveer al imperio de sucesores y forjar una alianza política más estrecha (Rodríguez López, 2016: 439). Como supuestamente dijo Mecenas, Augusto había hecho demasiado poderoso a Agripa como para ignorar su posición (DC 54.6.5). Agripa desempeñó una función elemental en los inicios del Imperio ${ }^{25}$. Tras su muerte, Tiberio asumió su misma posición tanto política como de marido de Julia (Vel. 2.95; DC 54.31.2). En ese caso ya no era necesario que tuviesen más hijos, dado que el futuro del Imperio estaba asegurado con los habidos con Agripa. Si la posición de Julia no se hubiese malogrado, claramente se le habría reservado un lugar de honor (similar

25. Fue el gran estratega militar de Augusto, responsable de las grandes victorias en Accio y Naulooco (DC 48-19.2-3; Vel. 2.85.2); se encargó del gobierno de Roma tras Accio, cuando Octavio seguía ocupado con los asuntos de Oriente (DC 51.3.5); fue uno de los dos cónsules del año 28 a. C. en que se retornó a la «normalidad republicana» (DC 53.1.1); ejerció como edil de Roma pese a ya haber sido cónsul con la intención de solventar algunos de sus problemas más acuciantes (Plin. NH 36.104; DC 49.43.1); entregó a Julia en matrimonio a Marcelo cuando Augusto no estaba disponible (DC 53.27.5); recibió un imperium proconsulare independiente y la tribunicia potestas (Vel. 2.93.3; Suet. Aug. 66.3; Tib. 10.1; DC 53.32.1); se casó el mismo con Julia y sus dos primeros hijos varones fueron adoptados por Augusto, etc. (Suet. Aug. 31.4; 63.1; DC 54.6.1-5; 18). 
al de Livia) como mujer del heredero en el momento en que Tiberio fue adoptado; que sería reforzado cuando este ejerciese el poder en solitario. Sin embargo, su historia tuvo un final abrupto. Ya fuese por el adulterio cometido con algunos de los herederos de familias de gran abolengo o por un supuesto intento de complot contra Tiberio y Augusto (Levick, 1972; 1976), Julia fue desterrada y no volvería a ver a su padre antes de su muerte ni a pisar Roma (Tac. Ann. 1.53; Suet. Aug. 65.3).

Tras este final prematuro, la imagen que conservamos de la única hija del emperador parece incompleta. Resulta evidente que disfrutó de un papel muy destacado en la sociedad de la época. Tras el nacimiento de Cayo se ordenó que este acontecimiento se celebrase cada año con un sacrificio público, lo cual honraba no solo al neonato y a Augusto, sino también a la madre que lo había traído al mundo (DC 54.8.5). En su función dinástica como madre de los herederos de Augusto fue honrada asimilándola a divinidades de la fecundidad, sobre todo en las representaciones artísticas de la mitad oriental del Imperio (Rose, 1997). En las fuentes escritas su protagonismo no es comparable al de Livia. Se alude a ella siempre en relación a los planes dinásticos de Augusto y uno de los pocos episodios en los que la vemos ocupar un lugar público de relieve es cuando ofrece un banquete para las mujeres de los senadores con motivo del triunfo de Tiberio (DC 54.2.4). Incluso en ese momento estará acompañada de Livia.

Pese a ser la única hija biológica del emperador, Julia nunca llegará a alcanzar la relevancia pública de Octavia y Livia. Es respetada como madre de los sucesores, pero no recibe los mismos honores por propio derecho que las mujeres de la generación anterior ${ }^{26}$. No podemos descartar que su abrupto final fuese lo que condicionase la condena de su memoria y que por ello no abunden las alusiones a su figura. En cualquier caso, todo parece indicar que el lugar principal estaba reservado, al igual que para el emperador, para la mujer que se encontrase a su lado, normalmente su esposa (Cid López, 2014: 186). Del mismo modo que el protagonismo del sucesor era secundario, también lo sería el de su esposa. Como ya mencioné, muy probablemente el papel de Julia hubiese tomado gran impulso de seguir casada con Tiberio a la muerte de Augusto.

Esta imagen de Julia nos sirve para demostrar que Augusto no estaba dispuesto a tomar decisiones revolucionarias con respecto a las mujeres de la familia. Dentro del nuevo régimen las mujeres tuvieron que

26. Es cierto que mientras que en las monedas de Augusto no aparece Livia, sí lo hace Julia (en el 13 a. C. coincidiendo con la época en que Livia se mantuvo más a la sombra, RIC 166a, BMC Augustus 109), pero solo porque en una acuñación en particular aparecen sus hijos. Julia está en calidad de madre, expresando la conexión entre su padre y los sucesores; su imagen queda relegada a un segundo plano y en una escala más pequeña (Barret, 2004: 208; Severy, 2010: 77). encontrar su nuevo espacio y lograr que sus nuevas funciones fuesen útiles para el emperador. Las decisiones de Augusto respecto a Livia y Octavia fueron novedosas y les otorgaron un papel nunca antes visto para las romanas. Sin embargo, Livia y Octavia se habían criado en un contexto republicano con los valores propios de las grandes matronas. Las fuentes destacan que Augusto imponía recato a las mujeres de su casa y que mantenía ciertos valores tradicionales, como que fuesen estas las que elaborasen los vestidos que él mismo utilizaba (Suet. Aug. 73.2).

Julia nació en un ambiente distinto: su juventud ya pertenece a la época en que su padre disfrutaba del poder en solitario. La mayor parte de los autores hablan de los comportamientos indecorosos de Julia en relación al motivo que provocó su exilio, pero Macrobio nos da algunos retazos de su comportamiento anterior (Mac. Sat. 5.1-9). La imagen general de Julia es la de una muchacha rica criada con todos los lujos de la corte que busca su propio bienestar. Macrobio afirma que abusaba no solo de la indulgencia, sino también de la fortuna de su padre, quien le había recordado en varias ocasiones que debía moderar su forma de vestir y su séquito. Las diferencias entre Julia y Livia, según este autor, no podían estar más claras. Para ella, ser la hija del César significaría una vida de lujos y excesos. Si lo que nos cuenta Macrobio es cierto, tendríamos a una muchacha criada en un contexto completamente distinto al de la crisis de finales de la República; que es consciente de la posición preeminente que ocupa ella misma y su familia, y que pretende disfrutar de una posición elevada y no del puesto eminente pero recatado que Augusto buscaba para sus mujeres (Hidalgo de la Vega, 2003: 52-53).

La historia de su supuesto idilio con los varones de las casas principales de la República y su comportamiento impropio (DC 55.210.12-14) iría en esta misma dirección. Las fuentes describen a una joven malcriada en los lujos de la corte, por lo que no estaría dispuesta a aceptar las órdenes de su padre respecto al comedimiento del que debía hacer gala. En este mismo sentido podemos entender la afirmación de Dion sobre el enfado de Augusto cuando se enteró de que sus nietos, los hijos de Julia, estaban siendo malcriados como niños de la corte (DC 55.9).

Teniendo en cuenta la versión de Levick (1972) sobre el destierro de Julia como resultado de un complot contra Tiberio y su padre que se buscó esconder bajo la acusación de adulterio, podríamos entender el testimonio de las fuentes sobre Julia como un resultado de la propaganda de Augusto. Este habría disimulado el intento de su hija por deponerlo mediante la acusación que con mayor frecuencia se dirigía contra las mujeres y que tenía que ver con el uso de su cuerpo. Propagado de esta manera por los medios de la época, la misma historia habría llegado hasta autores posteriores como Tácito o Dion.

Otra opción es que la capacidad de Julia para producir potenciales sucesores a través de sus relaciones 
adúlteras con hombres externos a la familia fuese considerada como uno de los mayores daños que podía provocar al nuevo régimen. Esto, sumado al nuevo clima social que Augusto quiso instituir a través de sus reformas sobre el matrimonio, ha llevado a autores como Severy (2010) a concluir que el gran pecado de Julia no debe buscarse en un intento de magnicidio, sino en ir en contra de la obra de su padre y dejar de ser ejemplo para la sociedad romana.

Algunas voces apuntan a que Julia ya habría sido infiel a Agripa (Mac. Sat. 2.5.1-10), pero Augusto lo habría dejado correr. Las tornas habrían cambiado en el momento en que inició una relación con Iulo Antonio que fue entendida como una amenaza para el régimen (Hallet, 2012: 376; Rodríguez López, 2016: 451).

Sea o no cierta la historia sobre Julia, lo que nos interesa considerar es la distinta forma en que las fuentes retrataron a las mujeres imperiales. Augusto vio el potencial de las mujeres de la familia como elementos de representación de su persona dentro del nuevo régimen y por ello les dio un puesto privilegiado. Sin embargo, no estaba dispuesto a llegar a ciertos extremos en la exaltación de los personajes femeninos. Es importante subrayar que, en esta época, la nueva posición de las mujeres debía derivar de los roles que tradicionalmente se les atribuían.

Julia era la única descendiente directa de la sangre de Augusto y, a través de él, del divino Julio y de Venus. De haber promovido su imagen por delante de las de Livia u Octavia, habría estado en mayor peligro de ser acusado de buscar una monarquía o un régimen de tipo helenístico. Era consciente del poder que aquel que se casase con su hija podía conseguir en el momento en que llegó a considerar el matrimonio con un caballero como forma de limitar el poder de su futuro yerno (Tac. Ann. 4.40.3; Suet. Aug. 63). Por ello, cuando Julia, por un motivo u otro, se salió de los patrones marcados, fue dejada de lado.

Augusto estaba dispuesto a otorgar un lugar especial a las mujeres, pero dentro de unos patrones de corte tradicional; no en vano buscaba promover un retorno a los valores antiguos para paliar la crisis moral (Balsdon, 1983: 78; Zanker, 1992: 128-129). Las mujeres le ayudarían a difundir su nuevo sistema, pero la directa intervención de estas en los asuntos políticos no llegaría hasta las siguientes generaciones. La posición otorgada a Livia y Octavia con las concesiones del 35 a. C. fue un hecho puramente instrumental dentro del contexto del momento, por lo que esos privilegios no se repitieron con más mujeres imperiales. El papel comedido que otorgó a sus familiares femeninas se constata en su ausencia en las Res Gestae; es decir, estas no son protagonistas, en ningún momento, de los actos que Augusto consideró clave en su vida. No así, por ejemplo, la efímera existencia de sus dos hijos adoptivos, Cayo y Lucio, quienes, pese a no haber llevado a cabo actos encomiables, si están presentes en la rendición de cuentas del primer príncipe $(R G 14)$

\section{POLÍTICA MATRIMONIAL}

Julia no fue la única sometida a los designios de Augusto. En una familia donde escaseaban los hombres, pero había gran cantidad de muchachas, estas tuvieron una importancia decisiva (Pani, 2003: 18). A través de ellas se pretendió generar apoyos al gobierno de Augusto y vincular a las partes julia y claudia de la familia ${ }^{27}$. Se buscó una ampliación controlada de la casa imperial (Hidalgo de la Vega, 2003: 51; 58), mediante matrimonios con individuos del círculo más cercano a Augusto (como el de Agripa con Julia, el de Enobarbo con Antonia Mayor o el de Druso con Antonia Menor), que diesen como resultado herederos para la familia y ayudantes para el poder imperial. Las siguientes generaciones se casaron de forma endogámica, y cada vez que un joven llegaba a la edad necesaria, el movimiento más prudente era el matrimonio dentro del entorno familiar para mantener el círculo de poder lo más cerrado posible. La consecuencia fue que la domus de Augusto se separó cada vez más del resto de casas aristocráticas y que aquellos que podían presumir de vínculos familiares con el núcleo de poder fueron vistos como especiales y diferentes ${ }^{28}$.

Corbier (1994a) realiza un completo análisis de los vínculos matrimoniales generados en época julio-claudia. En la época de Augusto serán esenciales las hijas de Octavia, como ya vimos, así como las de Julia a la hora de producir a los herederos de la siguiente generación y cerrar más los vínculos familiares del estrecho grupo de gobierno.

\subsection{LAS HIJAS DE OCTAVIA}

Solo los lazos matrimoniales de las descendientes de Octavia son tremendamente confusos y difíciles de seguir. Ya adelantábamos que, por medio de sus hijas, Octavia estaba relacionada con la gran mayoría de emperadores julio-claudios. Precisamente su hijo, aquel sobre el que Augusto depositaba sus esperanzas como único familiar directo varón, fue el único que murió sin

27. Es más, si atendemos a los matrimonios concertados en época de Augusto vemos que solo se permitió a las mujeres (a los muchachos no) casarse con individuos de otras familias y todo hace pensar que fue únicamente porque su número era demasiado grande como para encontrarles marido dentro del círculo más cercano. Además, cuando se permitió este tipo de uniones, fueron siempre con personajes sobresalientes de la antigua nobleza republicana. Para entender los complejos vínculos matrimoniales entre las élites romanas de la época ver: Syme, 1986.

28. Por ello Tácito consideró como un honor demasiado exagerado que Sejano, quien solo era un caballero, fuese a convertirse en el suegro del hijo de Claudio (Ann. 3.29.34). Pese a que Claudio era un miembro de segunda en el seno de la casa imperial, enlazar con él significaba entrar en el círculo más estrecho del emperador. En la misma línea Severy (2010: 66-67). 
descendencia. Por lo demás, Octavia contó con numerosa descendencia a través tanto de su matrimonio con Claudio Marcelo como con Marco Antonio.

\section{Con Claudio Marcelo:}

Marcela la Mayor. Casada en primeras nupcias con Agripa con la intención de vincular a este de forma más estrecha con Augusto (DC 53.1.2). Tuvieron varias hijas, de las cuales la más célebre es la Vipsania Agripina que se casó con Tiberio y fue madre de Druso. Después de su divorcio de Agripa, cuando este se casó con Julia, Marcela se esposó con Julo Antonio. Aunque tuvieron hijos, esta rama de la familia cayó en desgracia después de que Julo fuese declarado culpable de adulterio con Julia y obligado a suicidarse (DC 55.10.15).

Marcela la Menor. Casada con Mesala Apiano, fue madre de Claudia Pulcra y Valerio Mesala Barbato. La primera se casará con Quintilio Varo; lo que motivó que este fuese considerado parte de la familia y se le confiase una gran expedición en Germania. Mesala Barbato, como su nombre indica, será el padre de Mesalina junto a Domicia Lépida la Menor.

\section{Con Marco Antonio:}

Antonia la Mayor. Casada con Domicio Enobarbo ${ }^{29}$, fue la madre de la anteriormente mencionada Domicia Lépida, madre de Mesalina. Tuvo dos hijos más: uno de ellos, Domicio Enobarbo, fue el padre de Nerón a través de su matrimonio con Agripina la Menor. En su afán por cerrar cada vez más los vínculos familiares, Augusto acabó provocando que la mujer de un futuro emperador descendiese de Octavia tanto por parte materna como paterna; lo que da fe de lo necesario que fue mantener los matrimonios y la descendencia dentro del espacio controlado de la domus Augusta ${ }^{30}$. Aquellas mujeres que se casaron fuera de la familia, lo hicieron con descendientes de importantes líneas republicanas y se convirtieron en grandes apoyos en la política imperial.

Antonia la Menor. Prometida desde su infancia a Druso, hijo de Livia (Suet. Cal. 1.1; Clau. 1.6), fue el primer matrimonio concebido con la idea de acercar a las dos ramas de la familia. Serán padres de Germánico, quien volverá a casarse con descendientes directos de Augusto a través de Agripina (Suet. Aug. 64.1), hija de Julia y Agripa, y será padre del emperador Calígula y abuelo del emperador Nerón. Antonia y Druso también son padres del emperador Claudio y de su hermana Livila, casada primero con Cayo César y después con

29. Con su matrimonio con Antonia, Domicio Enobarbo se convertía en el primer hombre extraño a la familia, después de Agripa, en entrar en la domus (Pani, 2003: 37).

30. Ha de tenerse en cuenta que, aunque haga referencias a la domus Augusta como forma de agilizar la lectura, este término solo comienza a ser usado por Ovidio en sus escritos del exilio y aparece en los escritos oficiales (Tabula Siarensis) por primera vez en época de Tiberio (Corbier, 1994b; Pani, 2003: 18)
Druso el Menor. Tras la muerte de Druso, las fuentes informan de que Antonia decidió no volver a casarse (Val. Max. 4.3.3). Sin embargo, debemos tener en cuenta que en ese momento no parece que hubiese nadie disponible en la familia cercana para casarse con ella y que, dada su relevancia como sobrina de Augusto, cuñada de Tiberio y viuda del gran Druso, resultaría más prudente evitar un nuevo enlace para no otorgar legitimidad al poder imperial a un individuo extraño a la familia. Poco a poco se forjaba la idea de que las mujeres descendientes de Augusto eran capaces de transmitir, ellas solas, esta legitimidad.

Si bien siempre se ha acusado a Augusto de manejar el futuro de su hija Julia con sus sucesivos matrimonios, realmente la mayor parte de los vínculos de sangre que creó los diseñó a través de la descendencia de su hermana Octavia. El único lazo que se escapa de este esquema es el de Tiberio con Vipsania Agripina ${ }^{31}$, que dará como resultado a Druso el Menor, quien a su vez se casará con Livila, descendiente, una vez más, de Octavia.

\subsection{LAS HIJAS DE JULIA}

El siguiente matrimonio relevante es el de Agripa con Julia, que tendrá como fruto cinco hijos; de los cuales solo las dos hijas sobrevivirán lo suficiente como para tener sus propios descendientes. El matrimonio más relevante es el de Agripina con Germánico, destinado, una vez más, a unir ambas ramas de la familia (la de Agripina descendiente de Augusto y la de Germánico descendiente de Livia), y que ya se encuadra en los enlaces de la siguiente generación. Julia la Menor se casó con Lucio Emilio Paulo (descendiente del triunviro). Este enlace reunía a los descendientes de Augusto con la primera mujer de este, ya que Julia y Paulo eran primos, al proceder este de Cornelia, hija de Escribonia, madre de Julia y, al mismo tiempo, introducía la sangre de importantes hombres republicanos en la domus imperial.

\section{CONCLUSIONES}

A través de los ejemplos expuestos obtengo la impresión de que Augusto impulsó la imagen pública de las mujeres de su casa para cubrir tres funciones distintas.

31. No está claro si esta Vipsania era hija de Cecilia Ática o de Marcela. En caso de ser hija de la primera, se trataría de uno de los pocos matrimonios de hijos de la familia con mujeres externas y se explicaría dentro del momento temprano del Imperio en el que fue forjado el enlace y también como una manera de acercar a Agripa a la domus. En caso de ser hija de la segunda, presentaría una doble conexión de Tiberio, tanto con Agripa como con Octavia, y se encuadraría mejor dentro de los enlaces dinásticos. 
En primer lugar, una utilización de las figuras femeninas puramente circunstancial y con fines políticos, como es el caso de Octavia durante el triunvirato. Su historia personal se empleó para preparar a la opinión pública de cara a la guerra contra Marco Antonio y para demostrar que las ofensas contra la familia de Octavio eran ofensas contra el Estado. Debido a este motivo Octavia y Livia obtuvieron honores que nunca se habían dado en mujeres. Pero en sí todo el periodo del triunvirato destaca por las medidas excepcionales y la posición de las mujeres de los líderes en ese momento también lo fue. No obstante, tras la victoria en la guerra estas volvieron a la sombra, lo que lleva a pensar que, de haber dispuesto Octavio de otra excusa para iniciar las hostilidades, las dos matronas nunca habrían recibido tales honores.

La segunda función estaría íntimamente relacionada con la posibilidad de transmitir el poder mediante la sangre o el matrimonio (Corbier 1995; Hidalgo de la Vega, 2003; Cenerini, 2009). Las decisiones de Augusto en cuanto a la dinastía y a la política matrimonial determinarán que las mujeres tengan gran influencia en la transmisión del poder imperial. Si en la República las mujeres aristocráticas eran codiciadas como forma de establecer alianzas políticas, en el Imperio se llegará al siguiente nivel. Pese a que las mujeres no podrán ocupar el poder, el matrimonio con una de ellas aportará la legitimidad necesaria para participar en los asuntos de gobierno. Los matrimonios endogámicos permitieron que, en gran medida, las aspiraciones al poder quedasen dentro de la familia. La sucesión de Calígula, Claudio y Nerón probará que a la hora de demostrar quién poseía más antepasados relacionados con Augusto para legitimar su aspiración al Imperio, las mujeres también cuentan.

Los descendientes directos de Augusto disponían de la sangre divina de este y de Julio César y, a través de ellos, de Venus. Como bien le recordará Agripina a Tiberio, esa sangre divina también estaba presente en las mujeres (Tac. Ann. 52. 1-3) y ellas la podían transmitir. El resultado será que las mujeres solteras o viudas podían suponer un peligro para la estabilidad del poder al ser codiciadas por individuos ajenos a la dinastía.

Por último, Augusto impulsó una función con tintes más «institucionales», dentro de los límites en los que se encuadraban las acciones de unas mujeres que no podían desempeñar ningún papel oficial. De esta manera entenderíamos las apariciones públicas de las mujeres de la casa, como la inauguración de templos por parte de Livia, la presencia de estas en espectáculos públicos o en eventos religiosos. Las apariciones públicas estarían encaminadas a representar al emperador y su casa y podían tener lugar tanto en persona como mediante la exposición de imágenes femeninas en lugares públicos, que se inició en el 35 a. C. La proximidad de las mujeres imperiales con el poder dio un nuevo significado a actividades que antes serían normales y familiares, además de aportarles la capacidad de desarrollar actos públicos de un tipo distinto (Fischler, 1994: 122).
La concesión de favores, actos de beneficencia e intercesión en nombre de otros también forma parte de esta faceta de las mujeres imperiales. Esta capacidad permitía que el poder del emperador para ayudar a los demás se extendiese en un rango amplio.

Dentro de esta misma línea vemos que en época de Augusto se utiliza a las mujeres de su familia como ejemplo de los valores que pretendía inculcar a las matronas romanas (Fischler, 1994; Cenerini, 2002; Ginsburg, 2006; Cid López, 2014). El propio Augusto exaltó sus virtudes en el clipeus virtutis. Ya hemos visto como se destacaron sus principales valores como madres y esposas a través de sus donaciones arquitectónicas o, incluso, mediante los honores concedidos a Livia en el 9 a. C. en reconocimiento de su papel maternal. Así, estas facetas tuvieron ciertos precedentes republicanos y se establecieron dentro de la tradición. Augusto, seguramente, explotó todas las posibilidades que la presencia de las mujeres de su familia le ofrecían para afianzar su poder. No obstante, la posición de la emperatriz como revulsivo con funciones y valores nuevos se establece en el momento en que desaparece Augusto, con la publicación de un testamento que establece el nuevo rol a desempeñar por Livia, quien se convierte en Augusta.

Podemos ver, por lo tanto, que una vez tomado el poder en solitario en el 31 a. C., Augusto volvió a relegar a un segundo plano a sus familiares femeninas, que no volverían a tener protagonismo hasta que el régimen estuvo plenamente consolidado. Aun así, el papel que estas desarrollaron se encuadró dentro de unos patrones recatados y que entroncaban con la tradición anterior. El periodo anterior al 27 a. C. es confuso tanto en lo relativo a la posición de Octavio como en la imagen que se fue fraguando de su persona. Aunque parece haber sido consciente de la necesidad de evitar seguir el ejemplo de César, ciertas medidas de esa época recuerdan más a una monarquía que a la República ${ }^{32}$. De haberse construido un nuevo régimen que siguiese esa dinámica, posiblemente las mujeres habrían tenido un rol completamente distinto y más destacado. De hecho, ya vimos como las medidas del 35 a. C. fueron en cierta medida «revolucionarias» y no tienen eco en las demás concesiones de Augusto a las mujeres de su familia hasta que se desvelaron los legados de su testamento.

El frenazo y cambio de rumbo que se dio en los años 28-27 a. C. provocaron que se debiesen mantener ciertas apariencias. Livia, Octavia y Julia volvieron a quedar relegadas a la domus y no aparecen tan siquiera con motivo de los juegos Seculares del 17 a. C. A partir del 23 a. C. se reformulan los poderes de Augusto, el régimen sobrevive a un complot y en el 19 a. C. recibe nuevas atribuciones. Es a partir de ese momento cuando, plenamente consolidado el poder, se da pie a

32. Como puede ser la explotación de su vínculo divino con Apolo (Lambretchs, 1953: 65-82); la construcción de una casa-palacio conectada a un santuario, etc. 
una mayor centralización en la persona de Augusto y su familia, aunque haya que esperar hasta el 12 a. C. para la siguiente aparición de una imagen pública en la que apareciesen mujeres de su casa. Pese a ese cambio de dirección, la posición que desarrollan sigue fundamentada en la tradición, colaborando con el régimen, representando los valores impuestos por Augusto o haciendo obras de caridad y beneficencia, aunque en momentos también pudiesen ejercer influencia en temas políticos (las que se salían de este esquema, como Julia, se arriesgaban a ser relegadas). Esta última faceta será la que más se desarrolle con las sucesoras de Livia.

Tras la importante base sentada por Augusto a través de las concesiones a mujeres de su familia en vida y tras su muerte, los príncipes posteriores no harán sino explotar al máximo la función de los personajes femeninos en relación con el poder imperial, llegándose incluso a la primera consagración de un personaje femenino tan solo veinticuatro años tras la muerte de Augusto con Drusila, hermana de Calígula (DC 59.11; Suet. Cal. 24).

\section{REFERENCIAS}

Alexandridis, A. (2004). Die Frauen des römischen Kaiserhauses: eine Untersuchun ihrer bildlichen Darstellung von Livia bis Iulia Domna. Mainz: Philipp von Zabern.

Balsdon, J. P. V. D. (1983). Roman Women. Their history and habits. Connecticut: Greenwood Press.

Barret, A. A. D. (2004). Livia. Primera dama de la Roma imperial. Madrid: Espasa Calpe.

Bartman, E. (1999). Portraits of Livia. Imaging the imperial woman in Augustan Rome. Cambridge: Cambridge University Press.

Bartman, E. (2012). Early Imperial female portraiture. En S. L. James y S. Dillon. A companion to women in the Ancient World (pp. 414-422). Chichester: Willey - Blackwell. DOI: https://doi.org/10.1002/9781444355024.ch30

Bauman, R. A. (1992). Women and politics in Ancient Rome. London: Routledge.

Burns, J. (2007). Great women of Imperial Rome. Mothers and wives of the Caesars. London: Routledge. DOI: https:// doi.org/10.4324/9780203967072

Cid López, R. M. (1997). El protagonismo de las mujeres julio-claudias en la Domus Caesarum. En R. Urías Martínez, F. J. Presedo Velo, P. Guinea Díaz y J. M. Cortés Copete (Eds.). Chaire: homenaje al profesor Fernando Gascó (pp. 248-260). Sevilla: Scriptorium.

Cid López, R. M. (1998). Livia versus diva augusta. La mujer del príncipe y el culto imperial. Arys, 1, 139-155.

Cid López, R. M. (2014). Imágenes del poder femenino en la Roma antigua. Entre Livia y Agripina. Asparkía, 25, 179-201.

Cid López, R. M. (2016). Octavia. La noble matrona de la domus de Augusto. En R. Rodríguez López y M. J. Bravo
Bosch (Eds.). Mujeres en tiempos de Augusto: Realidad social e imposición legal (pp. 307-330). Valencia: Tirant Humanidades.

Cid López, R. M. (2018). Las Augustae en la dinastía Julio-Claudia. Marginalidad política, propaganda religiosa y reconocimiento social. En P. Pavón Torrejón (Ed.). Marginación y mujer en el Imperio romano (135-161). Roma Edizioni Quasar.

Cenerini, F. (2009). Dive e donne. Mogli, madri, figlie e sorelle degli imperatori romani da Augusto a Commodo. Imola: Angelini Editore.

Cenerini, F. (2016). Le matronae diventano augustae: Un nuovo profilo femminile. En F. Cenerini y F. Rohr Vio (Eds.). Matronae in domo et in re publica agentes. Spazi e occasioni dell'azione femminile nel mondo romano tra tarda repubblica e primo impero (pp. 23-49). Trieste: Edizioni Università di Trieste.

Corbier, M. (1994a). La maison des Césars. En P. Bonte (Ed.). Épouser au plus proche. Inceste, prohibitions et stratégies matrimoniales autour de la Méditerranée (pp. 243-291). Paris: Éditions de l'École des Hautes Études en Sciences Sociales.

Corbier, M. (1994b). À propos de la Tabula Siarensis: le Senat, Germanicus et la domus Augusta. En J. González (Ed.). Roma y las provincias: realidad administrativa $e$ ideología imperial (pp. 39-86). Madrid: Ediciones clásicas.

Corbier, M. (1995). Male power and legitimacy through women: the domus Augusta under the Julio-Claudians. En R. Hawley y B. Levick (Eds.). Women in Antiquity, new assesments (pp. 178-193). London: Routledge.

Cortés Tovar, R. (2005). Espacios de poder de las mujeres en Roma. En J. M. Nieto Ibáñez (Coord.). Estudios sobre la mujer en la cultura griega y latina. XVIII Jornadas de filología clásica de la Universidad de León (pp. 193-216). León: Servicio de publicaciones, Universidad de León.

Dennison, M. (2010). Empress of Rome: The life of Livia. Londres: Quercus. DOI: https://doi.org/10.3366/rom.2010.0103

Dixon, S. (1983). A family bussiness: women's role in patronage and politics at Rome, 80-44 B.C. Classica et Mediaevalia, 34, 91-112.

Domínguez Arranz, A. (2010). La mujer y su papel en la continuidad del poder. Iulia Augusti, ¿una mujer incómoda al régimen? En A. Domínguez Arranz (Coord.). Mujeres en la antigüedad clásica: género, poder y conflicto (pp. 153184). Madrid: Sílex.

Fantham, E. (2006). Julia Augusti. The emperor's daughter. London: Routledge. DOI: https://doi. org/10.4324/9780203392423

Fischler, S. (1994). Social stereotypes and historical analysis. The case of the Imperial women at Rome. En J. Archer, S. Fischler y M. Wyke (Eds). Women in ancient societies: an illusion of the night (pp. 115-133). London: Palgrave Macmillan. DOI: https://doi.org/10.1007/978-1-349-23336-6_7 
Flory, M. B. (1984). Sic Exempla Parantur: Livia's shrine to Concordia and the Porticus Liviae. Historia: Zeitschrift für Alte Geschichte, 33(3), 309-330.

Flory, M. B. (1993). Livia and the history of public honorific statues for women. Transactions of the American Philological Association, 118, 343-59. DOI: https://doi. org/10.2307/284333

Flory, M. B (1997). The meaning of Augusta in the JulioClaudian Period. American Journal of Ancient History, 13, 113-138. DOI: https://doi.org/10.31826/9781463237592-003

Frei-Stolba, R. (2008). Livie et aliae: Livie et aliae : le culte des diui et leurs prêtresses ; le culte des diuae. En F. Bertholet, A. Bielman y R. Frei-Stolba (Eds.). Egypte-Grèce-Rome. Les différents visages des femmes antiques. Berna: Peter Lang.

Gafforini, C (1994). Le mogli romane di Antonio: Fulvia e Ottavia. Rendiconti, Classe di lettere e science morali e storiche. Istituto lombardo, Accademia di scienze e lettere, $128,109-134$.

Ginsburg, J. (2006). Representing Agrippina. Constructions of female power in the early Roman empire. Oxford: Oxford University Press.

Gorrie, C. (2007). The restoration of the Porticus Octaviae and Severan Imperial policy. Grece \& Rome, 54, 1-17. DOI: https://doi.org/10.1017/S0017383507000010

Grether, G. (1946). Livia and the roman Imperial cult. The American Journal of Philology, 67, 222-252. DOI: https:// doi.org/10.2307/291543

Hallet, J. P. (2012). Women in Augustan Rome. En S. L. James y S. A. Dillon (Eds.). A companion to women in the Ancient World (pp. 371-384). Chichester: Willey-Blackwell. DOI: https://doi.org/10.1002/9781444355024.ch27

Hidalgo de la Vega, M. J. (2003). Esposas, hijas y madres imperiales. El poder de la legitimidad dinástica. Latomus, 62(1), 47-72.

Hidalgo de la Vega, M. J. (2012). Las emperatrices romanas. Sueños de púrpura y poder oculto. Salamanca: Ediciones Universidad de Salamanca.

Kajanto, I. (1972). Women's praenomina reconsidered. Arctos, 7, 13-30.

Kajava, M. (1994). Roman female praenomina: studies in the nomenclature of Imperial Rome. Roma: Institutum Romanum Finlandiae.

Lambretchs, P. (1953). La politique «apollinienne» d'Auguste et le culte impérial. La nouvelle Clio, 5, 65-82.

Levick, B. (1972). Tiberius' retirement to Rhodes in 6 B.C. Latomus, 31(3), 779-813.

Levick, B. (1976). The fall of Julia the younger. Latomus, 35(2), 301-339.

López, A. y Pociña, A. (2019). Las cartas de las mujeres de la familia de Augusto. En M. García Sánchez y R. S. Garraffoni (Coords.). Mujeres, género y estudios clásicos: un diálogo entre España y Brasil (pp. 205-214). Barcelona: Publicacions i Edicions de la Universitat de Barcelona.
Masi, C. (2016). Filvia. Nemica di Ottaviano e prima principessa romana. En R. Rodríguez López y M. J. Bravo Bosch (Eds.). Mujeres en tiempos de Augusto: Realidad social e imposición legal (pp. 209-236). Valencia: Tirant Humanidades.

Marengo, S. M. (2008). Octavia Soror Diui Augusti a Falerio. Picus, 28, 193-204.

Ortuño Pérez, M. E. (2016). Hortensia. Su discurso contra la imposición fiscal femenina. En R. Rodríguez López y M. J. Bravo Bosch (Eds.). Mujeres en tiempos de Augusto: Realidad social e imposición legal (pp. 367-400). Valencia: Tirant Humanidades.

Pani. M. (2003). La corte dei Cesari. Bari: Editori Laterza.

Paterson, J. (2007). Friends in high places: The creation of the court of the Roman emperor. En A. Spawforth (Ed.). The Court and Court Society in Ancient Monarchies (pp. 121156). Cambridge: Cambridge University Press.

Pflaum, H. G. (1960-1961). Les carrières procuratoriennes équestres sous le Haut-Empire romain I-III. Paris: Paul Geuthner.

Purcell, N. (1986). Livia and the womanhood of Rome. Proceedings of the Cambridge Philological Society, 32, 78-105. DOI: https://doi.org/10.1017/S0068673500004831

Rodríguez López, R. (2016). Julia Maior. La auctoritas de la gens Julia. En R. Rodríguez López y M. J. Bravo Bosch (Eds.). Mujeres en tiempos de Augusto: Realidad social e imposición legal (pp. 431-460). Valencia: Tirant Humanidades.

Rose, C. B. (1997). Dynastic commemoration and imperial porttraiture in the Julio-Claudian period. Cambridge: Cambridge University Press.

Salazar Revuelta, M. (2016). Livia. Modelo de princesa imperial en el marco del poder de la dinastía Julio-Claudia. En R. Rodríguez López y M. J. Bravo Bosch (Eds.). Mujeres en tiempos de Augusto: Realidad social e imposición legal (pp. 331-364). Valencia: Tirant Humanidades.

Saquete Chamizo, J. C. (2018). La Historia Augusta y las mujeres. En M. P. Pavón Torrejón (Ed.). Marginación y mujer en el Imperio Romano (pp. 315-332). Roma: Edizioni Quasar.

Scardigli, B. (1982). La sacrosanctitas tribunicia di Ottavia e Livia. Annali della Facoltà di lettere e Filosofia, Università di Siena, 3, 61-64.

Severy, B. (2010). Augustus and the family at the birth of the Roman empire. London: Routledge.

Singer, M. W. (1947). Octavia's mediation at Tarentum. The Classical Journal, 43(3), 173-178.

Soto Chica, J. (2016). Cleopatra. La reina de las tres cobras. En R. Rodríguez López y M. J. Bravo Bosch (Eds.). Mujeres en tiempos de Augusto: Realidad social e imposición legal (pp. 251-286). Valencia: Tirant Humanidades.

Syme, R. (1986). The Augustan aristocracy. Oxford: Clarendon Press. 
Tregiari, S. (1991). Roman marriage: Iusti coniuges fron the time of Cicero to the time of Ulpian. Oxford: Clarendon Press.

Wood, S. E. (1999). Imperial Women. A study in public images. B.C. 40-A.D. 68. Leiden: Brill. DOI: https://doi. org/10.1163/9789004351288
Woodhull, M. (2003). Engendering space. Octavia's portico in Rome. Aurora, 4, 13-33

Zanker, P. (1992). Augusto y el poder de las imágenes. Madrid: Alianza Editorial. 